\title{
Effect of electric field on one-quantum photodecay of oxygen-deficient centers in germanosilicate fibers
}

\author{
A. O. Rybaltovskii, Yu. S. Zavorotny, and P. V. Chernov \\ Skobel'tsyn Research Institute of Nuclear Physics, Moscow State University, 119899, Vorob'evy Gory, \\ Moscow, Russia \\ V. N. Bagratashvili and S. I. Tsypina \\ Institute of Laser and Information Technologies, Russian Academy of Sciences, 142092, Troitsk, Moscow \\ Region, Pionerskaya 2, Russia \\ P. G. Kazansky a) \\ Optoelectronics Research Center, University of Southampton, Southampton, S017 1BJ, United Kingdom
}

(Received 3 April 2000; accepted for publication 12 July 2000)

\begin{abstract}
The effect of a strong electric field (up to $10^{6} \mathrm{~V} / \mathrm{cm}$ ) on one-quantum UV photoexcitation and photodecomposition of germanium oxygen deficient centers (GODC) in twin-hole germanosilicate fibers with internal wire electrodes is reported. The fiber has been irradiated with the UV light of a deuterium lamp and triplet photoluminescence of GODC has been used to monitor the kinetics of its photodecay. Applying such an electric field did not affect the spectral characteristics of GODC but increased the rate of their one-quantum photodecomposition, while direct photoionization and charge separation did not take place. We have also shown that this effect is caused by the suppression of secondary photoinduced recombination processes of intermediates, rather than by acceleration of primary photodecomposition of GODC. (c) 2000 American Institute of Physics.

[S0003-6951(00)01437-6]
\end{abstract}

The effect of UV photosensitivity of Ge-doped silica glass is widely used for effective photoinscription of fiber and planar microstructures. ${ }^{1}$ This effect is recognized to be associated with structural phototransformation of germanium oxygen-deficient centers (GODC) and local density alteration in a Ge-doped glass network. Exposure of GODC to UV light is produced mostly in $242 \mathrm{~nm}$ singlet absorption band $\left(S_{0}-S_{1}\right.$ electron transition) and also in weak triplet absorption $330 \mathrm{~nm}$ band $\left(S_{0}-T_{1}\right.$ electron transition). ${ }^{2}$ Singlet photoexcitation of GODC results in the appearance of two luminescence bands-singlet band centered at about 300 $\mathrm{nm}\left(S_{1}-S_{0}\right.$ transition) and triplet band at about $400 \mathrm{~nm}$ ( $T_{1}-S_{0}$ transition). To increase the photosensitivity of germanosilicate glass the "chemical" pathways of UV energy relaxation in GODC should be accelerated. ${ }^{3-5}$ The mechanisms of GODC chemical phototransformation are very complicated, and they are far from being completely understood. Different parameters of glass such as concentration of $\mathrm{Ge}^{5,6}$ and other dopants ${ }^{7}$ and impregnated molecular species (like hydrogen ${ }^{5,8}$ ), can be critical for these mechanisms.

It should be noticed that the mechanism of charge (electron or hole) displacement has always been considered as an initial step of GODC phototransformation. This is why one of the possible approaches to control GODC phototransformation calls for the application of a strong electric field. ${ }^{9-11}$ It is important that depending on UV light intensity, both one-quantum and two-quantum GODC photodecomposition may occur. ${ }^{9,12}$ It was shown directly in Ref. 8, that UV photoexcitation of GODC with intense pulses of $\mathrm{KrF}$ laser $(\lambda$ $\left.=248 \mathrm{~nm}, \Phi>10^{-2} \mathrm{~J} / \mathrm{cm}^{2}\right)$ in an electric field results in ef-

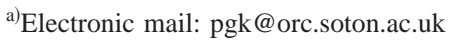

ficient two-quantum ionization of GODC and generation of photocurrent pulses. It has been observed in similar cases that the effects of a strong electric field on acceleration of both GODC decomposition ${ }^{10}$ and formation of Bragg gratings ${ }^{11}$ can be quite naturally attributed to the increase of displacement of charge carriers from ionized GODC and, as a result, to the suppression of recombination processes. The effects of a strong electric field on one-quantum photodecomposition of GODC is by no means apparent, since no free electrons are formed in this case. The objective of this work is to reveal such effects.

Two types of twin-hole fibers ${ }^{13,14}\left(18 \mathrm{~mol} \% \mathrm{GeO}_{2}\right.$ in the fiber core) were used in our experiments (Fig. 1): "thin" fiber (core diameter $3 \mu \mathrm{m}$, outer diameter $125 \mu \mathrm{m}$, distance

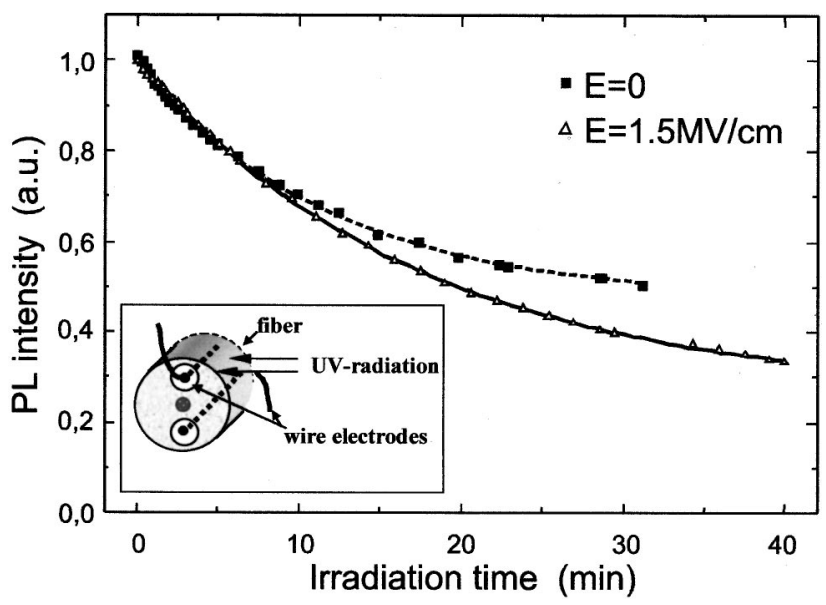

FIG. 1. Decay of triplet luminescence intensity in fibers as a function of the UV irradiation time from deuterium lamp. In the inset is the twin-hole fiber position during the irradiation. 


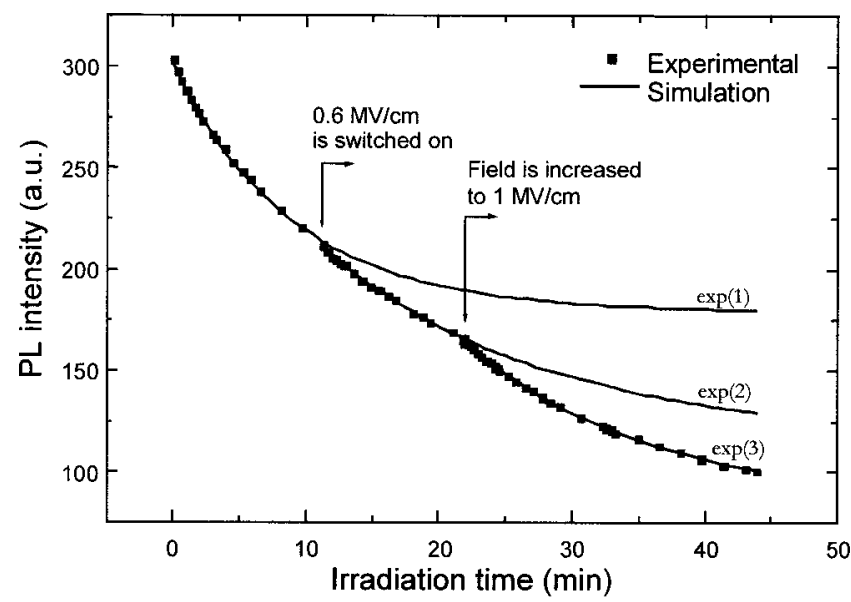

FIG. 2. Influence of successive electric field increase on the triplet luminescence signal kinetics. Experimental curve can be simulated by three successive exponents- $\exp (1), \quad \exp (2), \quad \exp (3)$ in the form of $y=y_{0}$ $+A e^{(1 / \tau)\left(x-x_{0}\right)}$

between capillaries $10 \mu \mathrm{m}$ ) and "thick" fiber (core diameter $6 \mu \mathrm{m}$, outer diameter $270 \mu \mathrm{m}$, distance between capillaries $30 \mu \mathrm{m})$. Gold-coated tungsten wire electrodes were inserted into the holes. dc voltage in the range of $0.1-3 \mathrm{kV}$ was applied to the electrodes which produced electric fields up to $E=10^{6} \mathrm{~V} / \mathrm{cm}$ inside a core.

The UV light (200-300 nm) of a deuterium lamp was used for the irradiation of the fibers (Fig. 1). The kinetics of GODC decomposition was monitored via the intensity of triplet photoluminescence (PL) of GODC at $400 \mathrm{~nm}\left(I_{T}\right){ }^{4}$ The signal of PL was detected through a fiber end by a photomultiplier. We also used germanosilicate films deposited on $\mathrm{SiO}_{2}$ substrates to monitor the behavior of GODC absorption band (by UV spectrometer) and UV induced paramagnetic species [by a $X$-band electron spin resonance (ESR) spectrometer $]^{5}$

Irradiation of GODC in germanosilicate samples (fibers and films) with the UV light from a deuterium lamp results in one-quantum decomposition of GODC, that is attended with degradation of GODC $242 \mathrm{~nm}$ absorption band and triplet luminescence signal $I_{T}$. Our ESR studies show the appearance and increase of signal from $\mathrm{GeE}^{\prime}$ centers. ${ }^{15}$ No other species like $\mathrm{Ge}(1)$ or $\mathrm{Ge}(2)$ are observed in ESR spectra (see also Refs. 5, 12, and 16). We observed that the rate of photodecomposition of GODC with the electric field applied, is always higher than that without the electric field (Fig. 1). The rate of GODC photodegradation $d N / d t$ undergoes an apparent sharp rise when the electric field is switched on or increased (Fig. 2). Oppositely, the switch off of the electric field results in a sharp decrease of GODC photodecomposition rate (Fig. 3). It is important to note that the change of the polarity of applied voltage during UV irradiation has no visible effect on the observed value of $I_{T}$ signal or its kinetics (Fig. 3). The latter observation indicates the absence of screening of the applied field via free electrons in the process of low intensity UV irradiation of GODC, which is in contrast to high-intensity UV irradiation. $^{9,17}$

To reveal possible effects of electric fields (up to $E$ $=10^{6} \mathrm{~V} / \mathrm{cm}$ ) on spectral parameters of GODC, we have measured the single-pulse temporal traces $\left(\tau_{T}=10^{-4} \mathrm{~s}\right)$ of triplet Downloaded 11 Nov 2009 to 152.78.208.72. Redistribution subject

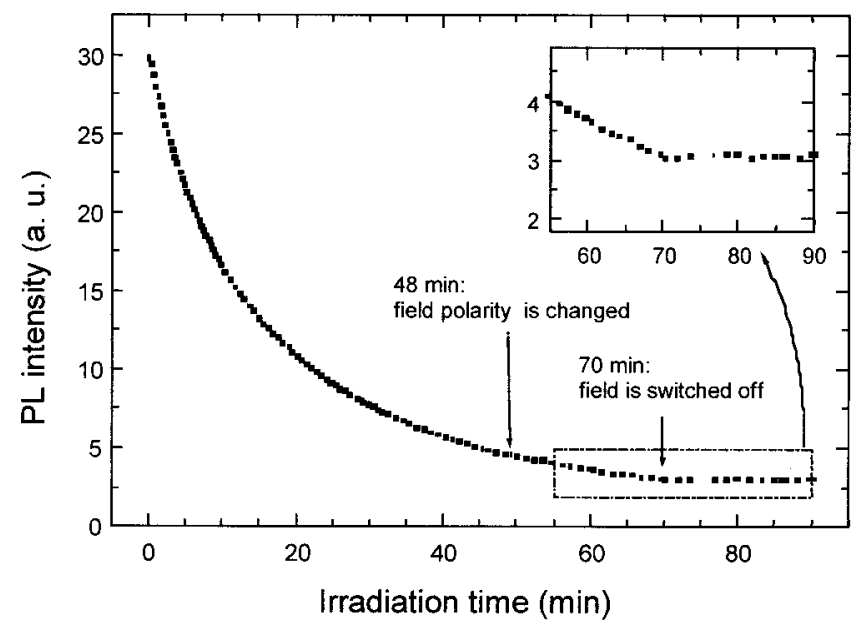

FIG. 3. Influence of the polarity change and switching-off electric field on the triplet luminescence signal kinetics.

luminescence of GODC at $400 \mathrm{~nm} I_{T}$ excited in our twinhole fibers with very low energy pulses of $\mathrm{KrF}$ laser $(\Phi$ $\left.=10^{-3} \mathrm{~J} / \mathrm{cm}^{2}\right)$ and $\mathrm{N}_{2}$ laser $(\tau=10 \mathrm{~ns}, \lambda=337 \mathrm{~nm}, \Phi$ $=10^{-4} \mathrm{~J} / \mathrm{cm}^{2}$ ). These fluence densities $\Phi$ provide the conditions for one-photon photoexcitation of GODC via singlet $S_{0}-S_{1}$ transition (for $\mathrm{KrF}$ laser) or triplet $S_{0}-T_{1}$ transition (for $\mathrm{N}_{2}$ laser). ${ }^{4}$ We did not observe any change in the amplitudes and temporal traces of $I_{T}$, when the electric field was applied.

Thus, two interesting conclusions could be made on the basis of our experimental results: strong electric field (up to $10^{6} \mathrm{~V} / \mathrm{cm}$ ) affects photoreactions, but does not affect the excitation and relaxation of $S_{1}$ and $T_{1}$ excited states of GODC. First, let us discuss the photoexcitation process. When GODC is excited in a singlet band, the population of $T_{1}$ state and the intensity of triplet relaxation $I_{T}$ is controlled by the cross section of UV absorption, the rates of singlet relaxation and intersystem crossing, and, finally, by the rate of triplet relaxation., ${ }^{2,4}$ Such insensitivity for electrically neutral GODC to electric field is of little or no surprise due to the fact that this field $\left(E=10^{6} \mathrm{~V} / \mathrm{cm}\right)$ is still much weaker than an intramolecular field $\left(10^{8} \mathrm{~V} / \mathrm{cm}\right)$. Consider next the possible effect of electric field on the triplet relaxation time $\tau_{T}$. Apart from electron radiation relaxation pathway of triplet excited GODC and phonon relaxation pathways there are also radiationless relaxation pathways that contribute to the triplet relaxation rate $1 / \tau_{T}$. Moreover, these radiationless pathways are those responsible for the decomposition and irreversible chemical transformation of GODC. The quantum yield of decomposition $q$ (the fraction of decomposed GODC per one absorbed UV photon) is usually very low $q \ll 1$. This means that "chemical" pathways resulting in irreversible photodecomposition of GODC are quite weak. Nevertheless, there are two examples ${ }^{4,5}$ where chemical pathways clearly contribute to $\tau_{T}$. First, the shortening of $\tau_{T}$ with Ge concentration observed in Ref. 4 is attributed to such a pathway (tunneling of electron from triplet excited GODC to another germanium trap). Secondly, significant (up to 50\%) shortening of $\tau_{T}$ has been observed in Ref. 5, caused by triplet excited GODC photoreaction with impregnated hydrogen. Since in our experiments the trace of triplet luminescence $\left(\tau_{T}\right)$ is almost insensitive to an electric field, it can also be o AlP license or copyright; see http://apl.aip.org/apl/copyright.jsp 
concluded that there is no effect of the electric field on primary photodecomposition probability of triplet excited GODC. On the other hand, the observed kinetics of triplet luminescence (Figs. 1-3) clearly demonstrate the effect of electric field on the photodegradation of GODC. It immediately follows that the electric field affects the secondary chemical processes of ionized GODC, such as the recombination processes. The stretched-exponential dependence of the kinetics of GODC photodecomposition (Figs. 1 and 2) could be explained by the photochemical inhomogeneity of GODC in a glass, when different groups of GODC have slightly different spectroscopic parameters and different photoreaction probabilities. . $^{3,18,19}$

It is commonly believed that the chemical transformation of the triplet excited state of GODC is caused by a tunneling charge transfer to traps located in a neighboring coordination shell, ${ }^{5}$ since no free electrons appear in this case. This effect has been treated as a transformation of triplet excited oxygen monovacancy from normal configuration to an anomalous one ("puckered" states). ${ }^{20}$ This process is accompanied by a transition of the three-coordinated oxygen atom to a positively charged state and also by a release of a free electron, which enters the Ge impurity zone, which is located nearby of a conductive band of $\mathrm{SiO}_{2}{ }^{20}$ The photoinduced decomposition of GODC described above is accompanied by the recombination process, when the photoactivation of the intermediates (the products of primary decomposition of GODC) results in restoration of GODC. Since some of these intermediates are charged species, it is reasonable to expect the influence of electric field on their photochemistry, which leads to the observed increase yield of GODC photodecomposition.

In summary, we have revealed the effect of a strong electric field (up to $10^{6} \mathrm{~V} / \mathrm{cm}$ ) on one-quantum UV photoexcitation and photodecomposition of GODC in a twin-hole germanosilicate fiber. The applied electric field does not affect the spectral characteristics of GODC, but increases the rate of their photodecomposition, despite the fact that a free electron formation and a charge separation does not occur. We have also shown, that this effect is caused by suppression of secondary photoinduced recombination processes of intermediates rather than by the acceleration of primary photodecomposition of GODC.
This research was supported by the Russian Foundation for Basic Research (Grant Nos. (C98-02-16728, (C97-0217244, and 96-15-96537). One author (A.O.R.) was supported by a Royal Society Fellowship at the ORC in Southampton.

${ }^{1}$ R. Kashyap, Opt. Fiber Technol.: Mater., Devices Syst. 1, 17 (1994).

${ }^{2}$ L. Skuja, J. Non-Cryst. Solids 149, 77 (1992).

${ }^{3}$ V. A. Radzig, V. N. Bagratashvili, S. I. Tsypina, P. V. Chernov, and A. O. Rybaltovskii, J. Phys. Chem. 99, 6640 (1995).

${ }^{4}$ Yu. S. Zavorotny, A. O. Rybaltovskii, P. V. Chernov, V. N. Bagratashvili, S. I. Tsypina, and L. Dong, Glass Phys. Chem. 23, 67 (1997).

${ }^{5}$ Yu. S. Zavorotny, A. O. Rybaltovskii, P. V. Chernov, V. N. Bagratashvili, V. K. Popov, S. I. Tsypina, and L. Dong, Glass Phys. Chem. 23, 444 (1997).

${ }^{6}$ L. Dong, V. N. Bagratashvili, S. I. Tsypina, Yu. S. Zavorotny, P. V. Chernov, A. O. Rybaltovskii, S. S. Alimpiev, and Ya. O. Simanovskii, Jpn. J. Appl. Phys., Part 1 37, 12 (1998).

${ }^{7}$ L. Dong, J. L. Cruz, L. Reekie, M. G. Xua, and D. N. Payne, IEEE Photonics Technol. Lett. 7, 1048 (1995).

${ }^{8}$ P. J. Lemaire, R. M. Atkins, V. Mizrahi, and W. A. Reed, Electron. Lett. 29, 1191 (1993).

${ }^{9}$ V. N. Bagratashvili, S. I. Tsypina, P. V. Chernov, A. O. Rybaltovskii, Yu. S. Zavorotny, S. S. Alimpiev, Ya. O. Simanovskii, L. Dong, and P. St. J. Russell, Appl. Phys. Lett. 68, 1616 (1996).

${ }^{10}$ M. Takanashi, T. Fujiwara, T. Kawachi, and A. J. Ikushima, Appl. Phys. Lett. 71, 993 (1997)

${ }^{11}$ Y. Guiquempois, G. Martinelli, P. Niay, P. Bernage, M. Douay, J. F. Bayon, and H. Poignant, Opt. Lett. 24, 139 (1999).

${ }^{12}$ J. Nishii, K. Fukumi, H. Yamanaka, K. Kawamura, H. Hosono, and H. Kawazoe, Phys. Rev. B 52, 1661 (1995).

${ }^{13}$ P. G. Kazansky, P. St. J. Russell, and H. Takebe, J. Lightwave Technol. 15, 1484 (1997)

${ }^{14}$ P. G. Kazansky and V. Pruneri, Phys. Rev. Lett. 14, 2956 (1997).

${ }^{15}$ E. J. Friebele, D. L. Griscom, and G. H. Sigel, J. Appl. Phys. 45, 3424 (1974).

${ }^{16}$ R. N. Schwartz and J. R. Blair, J. Appl. Phys. 65, 710 (1989).

${ }^{17}$ A. O. Rybaltovskii, V. N. Bagratashvili, P. V. Chernov, L. Dong, P. G. Kazansky, V. Pruneri, S. I. Tsypina, and Yu. S. Zavorotny, Tech. Dig. of Int. Conf. , 44 (1999).

${ }^{18}$ M. Poirier, S. Thibault, J. Lauzon, and F. Ouellette, Opt. Lett. 18, 870 (1993).

${ }^{19}$ V. N. Bagratashvili, S. I. Tsypina, V. A. Radtsig, P. V. Chernov, A. O. Rybaltovskii, S. S. Alimpiev, and Ya. O. Simanovskii, J. Non-Cryst. Solids 180, 221 (1995).

${ }^{20}$ E. M. Dianov, V. O. Sokolov, and V. B. Sulimov, Kvant. Elektron. (Moscow) 24, 617 (1997). 